\title{
EDUCAÇÃO AMBIENTAL COMO FERRAMENTA PARA O MANEJO DE RESÍDUOS SÓLIDOS NO COTIDIANO ESCOLAR
}

\author{
Girlene Santos de Souza ${ }^{1}$ \\ Poliana Brandão Machado² \\ Vanessa Ribeiro dos Reis ${ }^{3}$ \\ Aline Santos dos Santos ${ }^{4}$ \\ Viviane Borges Dias ${ }^{5}$
}

RESUMO: Este trabalho corresponde ao Projeto Utilixo: Uma Experiência de Educação Ambiental em Escolas Públicas Municipais de Cruz das Almas (BA) e foi desenvolvido com intuito de envolver a comunidade escolar nas questões ambientais, principalmente no que diz respeito à inadequada disposição do lixo. Tem como objetivo ressaltar a problemática dos resíduos sólidos, enfatizando a importância da reciclagem dos mesmos, através da coleta seletiva, mostrando seus benefícios ao meio ambiente e à comunidade, visando implementar práticas de Educação Ambiental nas escolas públicas municipais Recanto Feliz e Joaquim de Medeiros. Verificou-se, no final das atividades, que os educandos encontravam-se sensibilizados sobre os problemas ambientais da região da escola e motivados a atuarem na comunidade em prol do meio ambiente, propondo soluções adequadas para resolução de problemas relacionados à preservação ambiental.

Palavras-chave: Educação Ambiental; Coleta Seletiva; Reciclagem; Escola.

\footnotetext{
${ }^{1}$ Formada em Agronomia pela UFBA, Mestre em Ciências pela USP e Doutora em Fisiologia vegetal pela UFLA. Tem experiência em cultivo de Plantas Medicinais (Anatomia, morfologia e fitoquímica) além de trabalhar também com a área da Educação Ambiental onde desenvolve o Projeto Utilixo: uma experiência de educação ambiental em escolas públicas de Cruz das Almas aprovado pela FAPESB (edital 021/2010). E-mail:girlene@ufrb.edu.br.

${ }^{2}$ Discente do curso de Engenharia e Sanitária Ambiental da UFRB e bolsista FAPESB do Projeto Utilixo. E-mail: poliana_brandao@hotmail.com.

${ }^{3}$ Discente do Curso de Biologia-Licenciatura da UFRB e bolsista Pibex, trabalha com Educação Ambiental em escolas públicas do ensino infantil ao fundamental. E-mail: vanessareis19@hotmail.com. ${ }^{4}$ Discente do curso de Biologia- Licenciatura da UFRB, bolsista PET conexões de saberes, trabalha com projetos relacionados com a área da Educação Ambiental. E-mail: aline.santos58@yahoo.com.br.

Bióloga formada pela Universidade Estadual de Feira de Santana, Mestre em Educação e Contemporaneidade pela Universidade do Estado da Bahia. Especialista em Educação e Meio Ambiente (Faculdade de Artes do Paraná) e em Ensino de Ciências (Universidade de Brasília). Professora Assistente da Universidade Estadual de Santa Cruz (UESC), vinculada ao Departamento de Ciências Biológicas e professora de Biologia e Ciências da rede pública do Estado da Bahia. E-mail: vivianebdias7@yahoo.com.br.
}

Revbea, Rio Grande, V. 8, № 2:118-130, 2013. 


\section{INTRODUÇÃO}

$\mathrm{Na}$ Idade Média o lixo acumulava-se pelas ruas e imediações das cidades, provocando sérias epidemias e causando a morte de milhões de pessoas. A partir da Revolução Industrial iniciou-se o processo de urbanização, provocando um êxodo do homem do campo para as cidades. Observou-se assim um vertiginoso crescimento populacional, favorecido também pelo avanço da medicina e consequentemente aumento da expectativa de vida. A partir de então, os impactos ambientais passaram a ter um grau de magnitude alto, devido aos mais diversos tipos de poluição, dentre eles a poluição gerada pelo lixo.

O fato é que o lixo passou a ser encarado como um problema, o qual deveria ser combatido e escondido da população. A solução para o lixo naquele momento não foi encarada como algo complexo, pois bastava simplesmente afastá-lo, descartando-o em áreas mais distantes dos centros urbanos, denominados lixões (FADINI et al., 2001).

De acordo com os dados do Ministério do Meio Ambiente, o Brasil gera em média 90 milhões de toneladas de lixo por ano e cada brasileiro produz, aproximadamente, 500 gramas de lixo por dia, podendo chegar a mais de $1 \mathrm{~kg}$. Dentre os resíduos sólidos (lixo) produzidos no país, $76 \%$ são jogados nos lixões (amontoamentos de lixo em um terreno, sem tratamento) e outros 13\% nos chamados aterros controlados (FADINI et al., 2001), gerando assim vetores que serão proliferadores de doenças.

A disposição final dos resíduos orgânicos em lugares inadequados pode afetar também a saúde dos seres humanos, por causa dos gases que são emitidos pelo processo de decomposição como: metano, dióxido de carbono, sulfídrico, amônia e outros ácidos orgânicos voláteis. Apenas $10 \%$ do total coletado têm como destino final os aterros sanitários, onde se diferencia pelo tratamento do chorume. Sendo que algumas cidades brasileiras atiram o lixo nas ruas, terrenos baldios, rios, lagos, lagoas e no mar.

A destinação adequada dos resíduos sólidos é um dos grandes problemas enfrentados nas cidades brasileiras, sendo estimulada pelo aumento da produção cada vez mais de dejetos. De acordo com a Associação Brasileira de Empresas de Limpeza Pública e Resíduos, cada brasileiro produziu em média 378 quilos de resíduos em 2010, contra os 359 quilos registrados em 2009.

Nesta perspectiva, a Educação Ambiental tem uma importância fundamental, pois permite a solução de vários problemas em nossa vida e novas ideias para a comunidade. Em concordância com essa ideia, Zuben (1998) afirma que o projeto de coleta seletiva nas escolas é muito importante, pois incentiva os alunos desde já a separarem o lixo, levando esse hábito para suas casas. Por isso o autor destaca que uma das principais alternativas para diminuir o problema do lixo é a reciclagem. Dessa forma, a Educação Ambiental deve ser praticada desde o Ensino Fundamental. 
Para Penteado (2007), a escola é um local adequado para a construção da consciência ambiental através de um ensino ativo e participativo, superando as dificuldades encontradas nas escolas, atualmente moldadas pelos modos de ensino tradicionais. Comportamentos ambientalmente corretos devem ser aprendidos na prática, e a escola, pode contribuir significativamente para esse processo através da formação de sujeitos críticos e reflexivos capazes de atuar na complexa realidade socioambiental, contemplando sua pluralidade de aspectos. É indiscutível a necessidade de conservação e defesa do meio ambiente, para tanto, a escola precisa empreender esforços para que os alunos compreendam que as questões ambientais envolvem além das questões relacionadas ao ambiente físico, aspectos sociais, econômicos, políticos e históricos. Nessa perspectiva, a Educação Ambiental discute de forma ampla, as relações sociedade-meio ambiente, articulando o sujeito para refletir, bem como buscar meios para intervir nos problemas e conflitos ambientais (CARVALHO, 2004).Para tanto é importante que se trabalhe a Educação Ambiental dentro e fora da escola, elaborando e inserindo projetos que envolvam os alunos (SANTOS, 2010).

A questão ambiental requer novas formas de abordagem, integrando as várias áreas de conhecimentos e tendo como foco principal o despertar da consciência, principalmente das crianças e dos adolescentes, para que assim novos hábitos possam ser formados, direcionando a espécie humana a utilizar os recursos naturais de forma sustentável. Diante dos fatos, faz-se necessário e urgente o desenvolvimento de programas e ações de caráter educativo que incitem e provoquem uma mudança profunda e progressiva na escala de valores e atitudes dominantes na sociedade atual (OLIVEIRA, 2009). Para que possa funcionar a interação escola e Educação Ambiental, juntamente com o incentivo didático, várias oficinas de ensino podem ser aplicadas, como por exemplo, a reutilização de materiais recicláveis na escola. Essa ideia fica ainda mais prática e interessante se houver uma junção de reutilização de materiais, criando objetos com material reciclado, que possa ser útil em sala de aula, ajudando no ensino e na didática dos alunos.

A educação ambiental é um processo de reconhecimento de valores e clarificações de conceitos, objetivando o desenvolvimento das habilidades e modificando as atitudes em relação ao meio, para entender e apreciar as interrelações entre os seres humanos, suas culturas e seus biofísicos, estando também relacionada com a prática e a ética, que conduzem para a melhoria da qualidade de vida (GUARIM, 2002).

De acordo com Cempre (2006), a Educação Ambiental com relação aos resíduos sólidos deve ser difundida tendo como foco os três R's (Reduzir, Reutilizar, Reciclar), sensibilizando e informando a sociedade, com o objetivo de aumentar a consciência ambiental desta.

Atualmente, as práticas de Educação Ambiental têm sido propostas por vários autores. De uma forma bastante abrangente, percebemos que essas categorizações geralmente partem de uma concepção mais ligada aos aspectos naturais, até chegar a uma concepção relacionada a uma visão mais

Revbea, Rio Grande, V. 8, № 2:118-130, 2013. 
integrada do meio ambiente, incluindo questões culturais, sociais, históricas, entre outras (CARVALHO, 2002).

Este trabalho vem com a proposta de aplicar um projeto de Educação Ambiental com crianças do ensino fundamental nas escolas públicas, Recanto Feliz e Joaquim de Medeiros do município de Cruz das Almas - BA, com o intuito de despertar a responsabilidade socioambiental da população e colaborar para a melhoria da qualidade de vida, promovendo palestras para conscientizar os estudantes sobre os problemas ambientais da sociedade, em especial, sobre o lixo, seu destino e possíveis formas de reaproveitamento.

\section{METODOLOGIA}

O trabalho foi desenvolvido nas Escolas Municipais Recanto Feliz e Joaquim de Medeiros, localizada nas proximidades da Mata de Cazuzinha (local de importante preservação ambiental) e no entorno da Universidade Federal do Recôncavo da Bahia, respectivamente, no município de Cruz das Almas, Bahia, no período de fevereiro a dezembro de 2011. O público participante foram os professores e os alunos pertencentes ao segundo, terceiro e quarto ano do turno matutino do ensino fundamental com idades entre 9 e 12 anos.

Para início do trabalho foi feito um levantamento sobre as questões ambientais e os impactos gerados pelo lixo, através da aplicação de um questionário (Anexo), junto à direção e à coordenação das escolas, com o objetivo de conhecer como o tema "Meio Ambiente e Lixo" são abordados nas escolas. Diante desse questionário foi traçado o perfil ambiental das escolas em relação às questões de Educação Ambiental.

A segunda etapa foi à apresentação do projeto para os professores e alunos, utilizando vídeos e imagens, levando também alguns questionamentos aos mesmos, em relação ao meio ambiente e aos resíduos sólidos.

Foram realizadas algumas palestras que tiveram como objetivo enfocar - lixo como poluição, e os possíveis riscos acarretados à saúde pública, sempre relacionada à importância da Educação Ambiental e do acondicionamento para a solução de tal problema. Estas palestras foram efetuadas utilizando vídeos educativos, cartazes elaborados pelos alunos e folhetos informativos, objetivando o esclarecimento de alguns conceitos, através da entrevista realizada, tais como: lixo domiciliar e escolar; tempo de decomposição; destino do lixo; poluição gerada pelo lixo; coleta seletiva; compostagem assim como, os problemas acarretados pelo lixo para o homem e para o meio ambiente tendo como intuito inserir, no contexto escolar, uma discussão complementar sobre o assunto.

Posteriormente, foram realizadas atividades práticas e oficinas, com materiais recicláveis, onde se trabalhou com o manejo do lixo. Ao mesmo tempo foi feito a caracterização do lixo gerado na cozinha das escolas, onde se constatou de forma geral que o mesmo era constituído de embalagens de 
plásticos, papéis, enlatados, guardanapos de papel, palitos de dente, poeira proveniente da varrição do refeitório e cozinha, cascas de frutas, cascas de verduras, restos de comidas, bem como restos de leite e pães que sobravam do lanche.

Após a caracterização dos resíduos da cozinha das escolas, para iniciar a prática da compostagem, realizou-se reuniões com as funcionárias responsáveis pela cozinha para explicar a respeito da compostagem doméstica e da sua importância para o meio ambiente, bem como do valor do composto como adubo orgânico. Também foi passada uma lista de materiais que poderiam ser desviados para a composteira, explicando que a separação do lixo inerte do orgânico, no momento que eram gerados, sendo importante para obter um adubo de boa qualidade.

Foram utilizados vídeos educativos: "Lixo é no lixo"; "Salve o planeta"; "A história das cosias"; "Os sem floresta" que tratava de diversos temas relacionados ao meio ambiente, onde o enfoque maior foi o tema "Lixo". Uma outra atividade desenvolvida foi à coleta seletiva domiciliar/escolar, onde os discentes, uma vez por semana, separavam e acondicionavam o lixo escolar e os resíduos sólidos domiciliares, que eram trazidos até a escola, em seguida 0 lixo era encaminhado para a INCUBA (Incubadora de Empreendimentos Solidários), instalada no município em questão, que ficava encarregada de repassá-lo às empresas responsáveis pelo destino final do mesmo, a reciclagem.

Para consolidarmos o conhecimento sobre a temática lixo, foram elaborados cartilhas, folders, jornal informativo, sendo que os mesmos foram distribuídos na comunidade escolar, incluindo os pais, além da criação de um blog do Projeto Utilixo, (http://projetoutilixoufrb.blogspot.com/), buscando dessa forma contribuir com ampliação da participação das pessoas na preservação do meio ambiente, através da dissipação de informações.

\section{RESULTADOS E DISCUSSÃO}

Os resultados dos questionários aplicados aos diretores e coordenadores das escolas mostraram que existem trabalhos feitos por professores, ligados ao meio ambiente. Porém nem todos os professores discutem ou aplicam, de forma transversal, a Educação Ambiental. As principais dificuldades dos professores dizem respeito às questões orçamentárias e estruturais, como, também, à motivação, capacitação e compreensão do tema, além de dificuldades de relacionamento entre si e em liderar projetos e comprometer-se com o seu andamento. De acordo Bizerril e Faria (2001), a parceria entre centros de pesquisa e as escolas é considerada como primordial na busca de mudanças neste quadro.

No trabalho sobre Educação Ambiental no ensino fundamental desenvolvido por Gama e Borges (2010) ficou evidenciado que, embora os professores do Ensino Fundamental de uma escola em Uberlândia entendam a 
essência da Educação Ambiental, a maioria ainda tem certa dificuldade de colocá-la em prática

A Educação Ambiental na formação dos professores é uma necessidade premente. Nos Parâmetros Curriculares Nacionais (PCNs) a Educação Ambiental é uma aliada de todas as disciplinas justamente por dar ao enfoque ambiental uma perspectiva diferenciada dentro de cada disciplina proporcionando um grande leque de possibilidades de trabalhos que envolvam o meio ambiente.

Foi mostrada também pela direção a grande quantidade de alunos nas salas de aula, impossibilitando a realização de atividades, por conta do tempo. De acordo com os questionários constatou-se a ausência de coleta seletiva na escola, apesar de existirem nas salas pequenas lixeiras apropriadas para tal atividade.

A partir desse perfil ambiental observado no questionário, deram-se início as palestras bem como os seminários durante as visitas nas escolas. Também foram desenvolvidas atividades práticas em sala de aula e apresentações de vídeos educativos relacionados ao meio ambiente e ao lixo.

As atividades de educação ambiental apresentaram resultados satisfatórios, promovendo a disseminação da informação e conscientização de alunos, professores e funcionários. Os vídeos, músicas, interações e conversas com os alunos trouxeram grandes avanços fazendo com que as crianças desenvolvessem um censo crítico e um pensamento de buscar a solução para alguns problemas ambientais. A partir dos materiais recicláveis como papelões e tampinhas de garrafa pet, os alunos confeccionaram brinquedos, jogos (da velha e do ponga) e cartazes que foram expostos na escola (Figuras 1, 2, 3). Nesse contexto foi trabalhada de forma transversal a disciplina matemática na formação desses jogos.
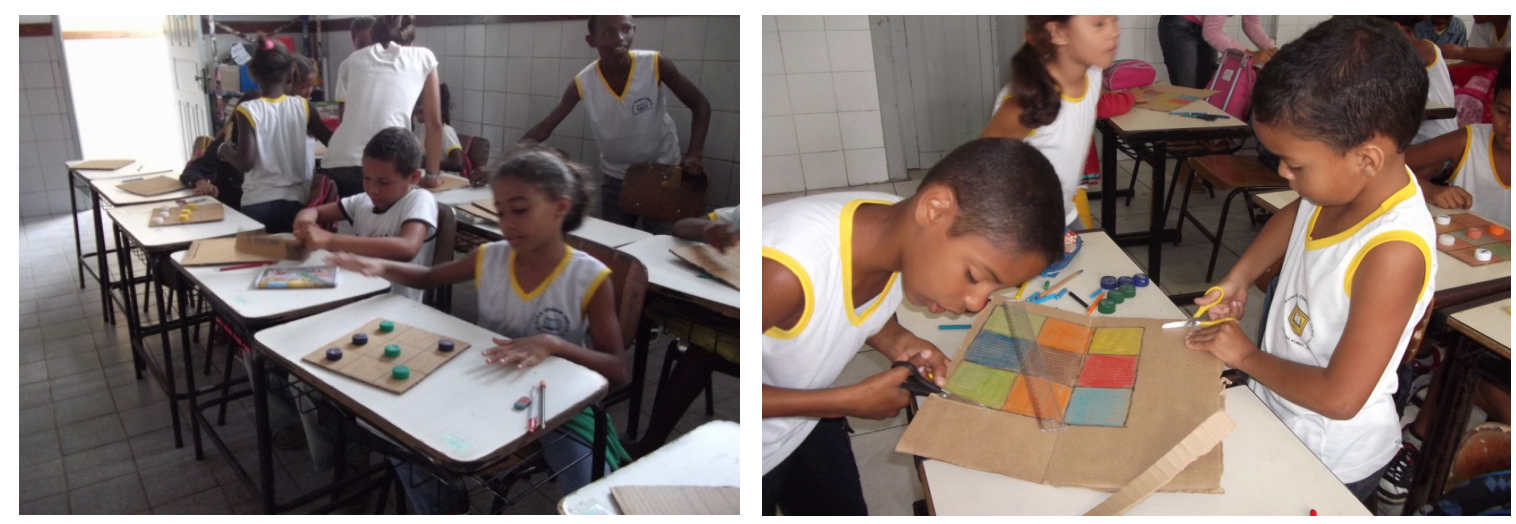

Figura 1: A: Alunos da Escola Joaquim de Medeiros construindo o jogo da velha com papelão e tampinhas de garrafa pet; B: Alunos da Escola Recanto Feliz confeccionando o jogo da ponga. 

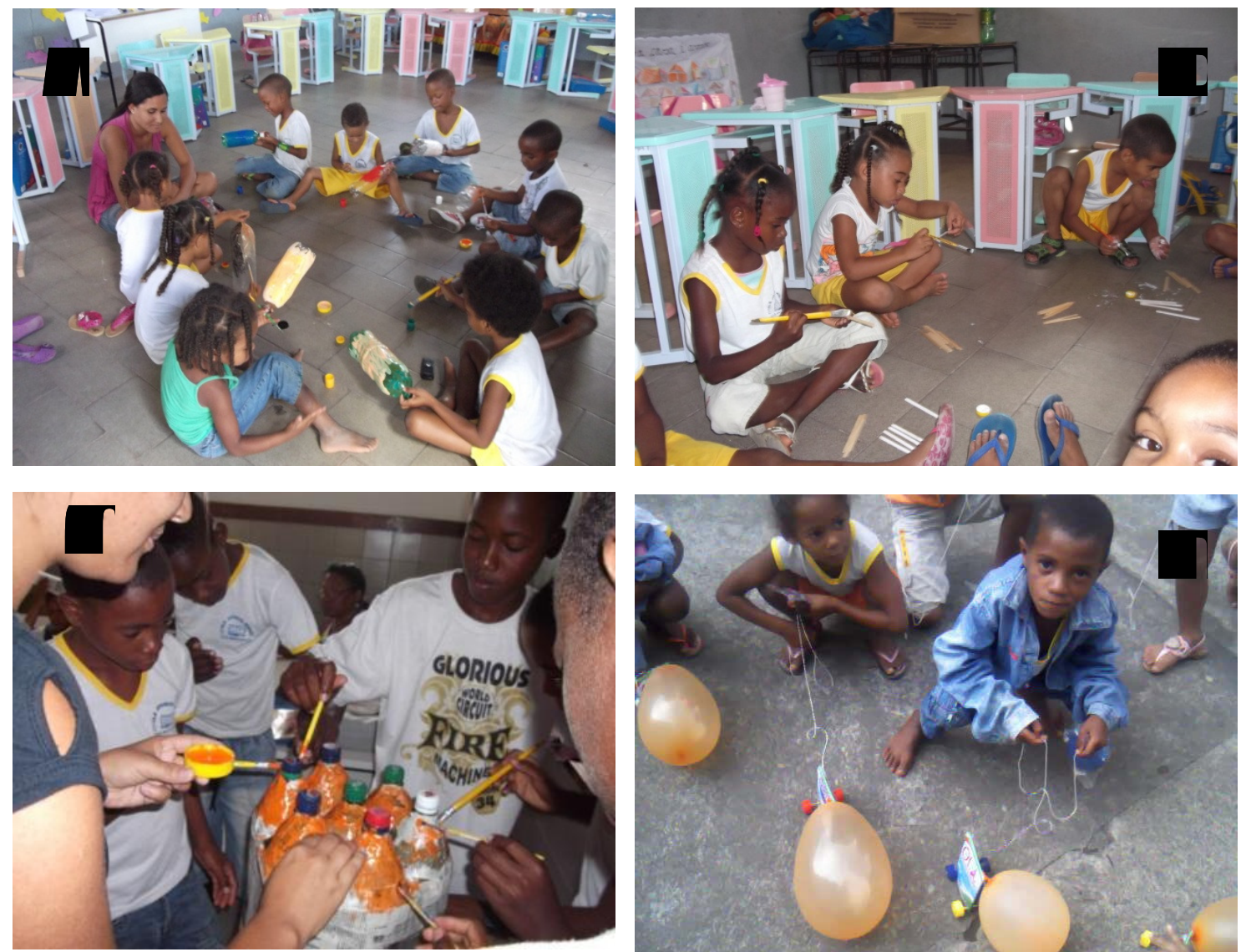

Figura 2: Oficina de reutilização: A e D: Alunos da escola Joaquim de Medeiros confeccionando cavalinhos com garrafa pet; B: Alunos da escola Joaquim de Medeiros confeccionando arte de natal com palitos de picolé; C: Alunos da escola Recanto Feliz na construção do puff com garrafa pet.

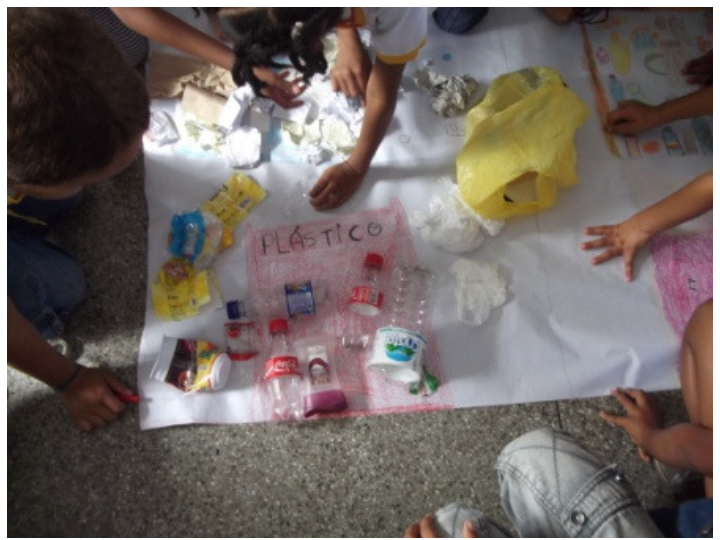

Figura 3: Alunos da escola Recanto feliz confeccionando cartaz vivo mostrando o tempo da duração de decomposição de alguns produtos.

Em uma das aulas práticas, foi feito à separação do lixo oriundo das salas de aula e trazidos de casa, onde foram utilizadas pequenas lixeiras

Revbea, Rio Grande, V. 8, N² 2:118-130, 2013. 
seletivas nas cores verde (para vidro), azul (para papel), amarela (para metal) e vermelha (para plástico) já existentes nas Escolas, para os estudantes, com o uso de luvas plásticas, pegarem os lixos e colocarem nas lixeiras adequadas (Figuras 4 e 5).

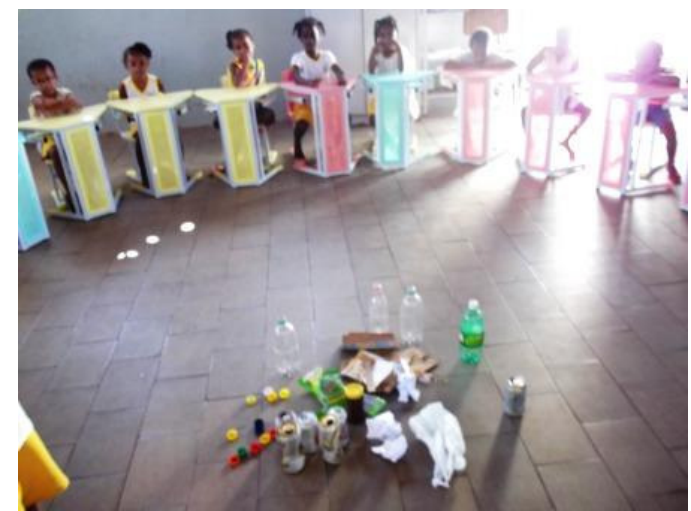

Figura 4: Atividade prática sobre a coleta seletiva com os alunos da escola Recanto feliz
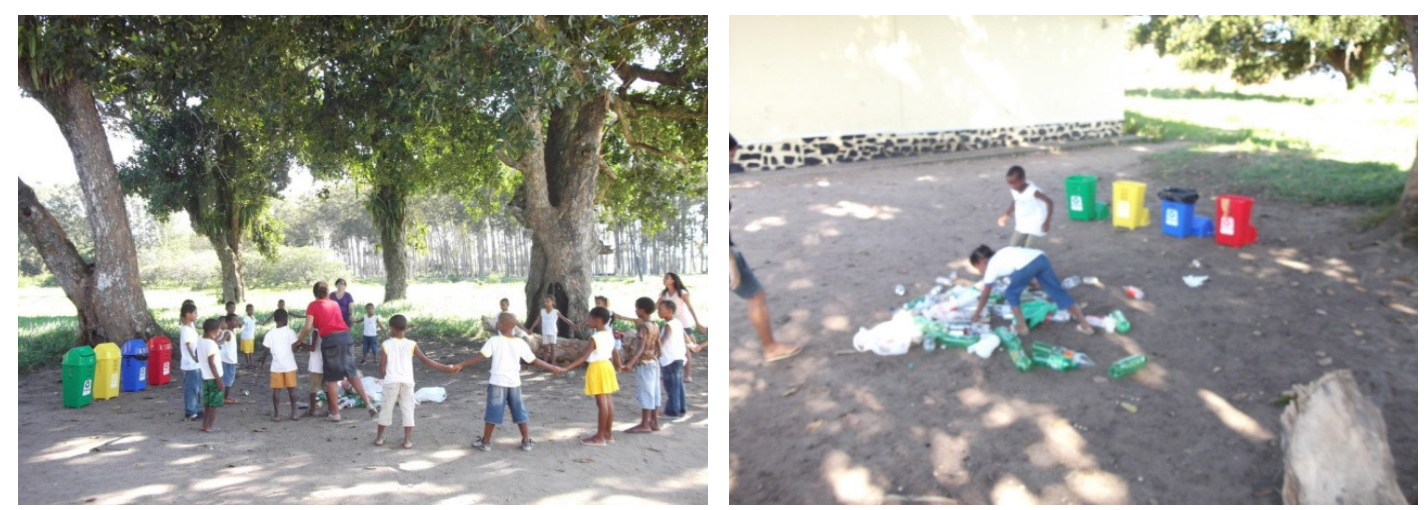

Figura 5: Atividade sobre a coleta seletiva na área externa da escola Joaquim de Medeiros.

No decorrer do trabalho, foram feitas palestras relacionadas aos seguintes temas: lixo e suas classificações, destino do lixo, poluição urbana, doenças e o lixo, sustentabilidade, os 3R's, coleta seletiva, tempo de decomposição, compostagem dentre outros. Foram levantados questionamentos aos alunos como: "O que vocês entendem como utilixo?", "Quais as consequências do lixo jogado na natureza e para o homem?", "O que significa coleta seletiva?", "Para onde o lixo da sua casa e da escola é levado?", "O que vocês entendem por decomposição?", "Vocês sabem o que é Reciclagem?".

Na primeira apresentação do trabalho, foram mostradas imagens de um pátio escolar cheio de lixo, de cadeiras escolares quebradas e sem utilidade, e as lixeiras da coleta seletiva. Posteriormente, apresentou-se também um vídeo educativo com personagens falando sobre as consequências do lixo jogado na natureza e imagens do planeta com os efeitos da poluição. Em outra atividade as crianças assistiram a um vídeo educativo animado que falava sobre 0 
sofrimento do planeta terra e dos animais com o acúmulo de lixo, gases, desmatamento, poluição das águas e aquecimento global.

$\mathrm{Na}$ segunda palestra foi apresentado o conceito de lixo segundo Luiz Mário Queiroz Lima, em seu livro: LIXO - TRATAMENTO E BIORREMEDIAÇÃO (1995: p.11), que define o lixo como todo e qualquer resíduo que resulte das atividades diárias do homem na sociedade. Mostrouse também a classificação do lixo, como: residencial, comercial, especial, hospitalar e industrial; assim como o tempo de decomposição dos materiais presentes no cotidiano dos estudantes, como: chiclete, plásticos, papel e madeira.

Posteriormente foi apresentada uma palestra sobre o que é a coleta seletiva, sua importância para o meio ambiente e o que é feito com o material recolhido e sua transformação em novos materiais. Em outra palestra que teve como tema, destino do lixo, onde foi questionado para onde era encaminhado o lixo da sua casa e da escola; alguns alunos tinham o conhecimento do "Lixão", mas não sabiam sobre "Aterro Sanitário". Mostraram conhecimento sobre compostagem e um pouco sobre reciclagem. Foi dito também, sobre o processo de incineração, salientando as vantagens e desvantagens de todos os destinos do lixo.

De acordo com Abreu et al. (2008), muitos alunos acreditam que não jogar lixo no chão ou em lugares inadequados representa uma importante contribuição na preservação da natureza. No trabalho desenvolvidos por estes autores constatou-se que apenas $8 \%$ das ações propostas abrangeram a diminuição no consumo de produtos industrializados como forma de reduzir o lixo gerado.

Percebeu-se que durante as palestras e até mesmo nas atividades práticas, os estudantes relatavam sobre situações vivenciadas ligadas ao lixo, como por exemplo, a rua em que moram apresenta um terreno baldio cheio de lixo, familiares que ficaram doentes por conta de vetores que habitam lugares onde há o acúmulo do lixo e água parada. Apresentaram também situações que presenciaram no momento de lazer, como por exemplo, praias sujas de copos e pratos plásticos.

Com as palestras e atividades práticas, os estudantes foram estimulados a colaborar para a melhoria da à qualidade de vida, com a conscientização sobre questões ambientais ligadas ao lixo na área da escola, como na cidade de Cruz das Almas.

De acordo Tavares (2010), ao desenvolver um projeto de Educação Ambiental na Escola Municipal Vitor Miguel de Souza, em Florianópolis, observou que o as crianças foram incentivadas a considerar o meio ambiente e a perceberem que fazem parte dele, que são sujeitos importantes, com direitos e deveres em relação ao Planeta Terra.

Com o auxílio da separação adequada dos alimentos e a ajuda de funcionários, foi possível desenvolver nos fundos da escola Recanto Feliz uma composteira de fácil manutenção (Figura 6). Assim, com a prática da Revbea, Rio Grande, V. 8, N²:118-130, 2013. 
compostagem foi possível despertar a atenção dos alunos com relação ao desperdício e a importância de encontrar alternativas criativas e viáveis, que no mínimo, amenizem os impactos ambientais. Através deste trabalho mostrou-se um envolvimento da comunidade escolar no processo de construção de alternativas à degradação ambiental, que tem como produto final o adubo orgânico, que é devolvido ao ciclo habitual da natureza.
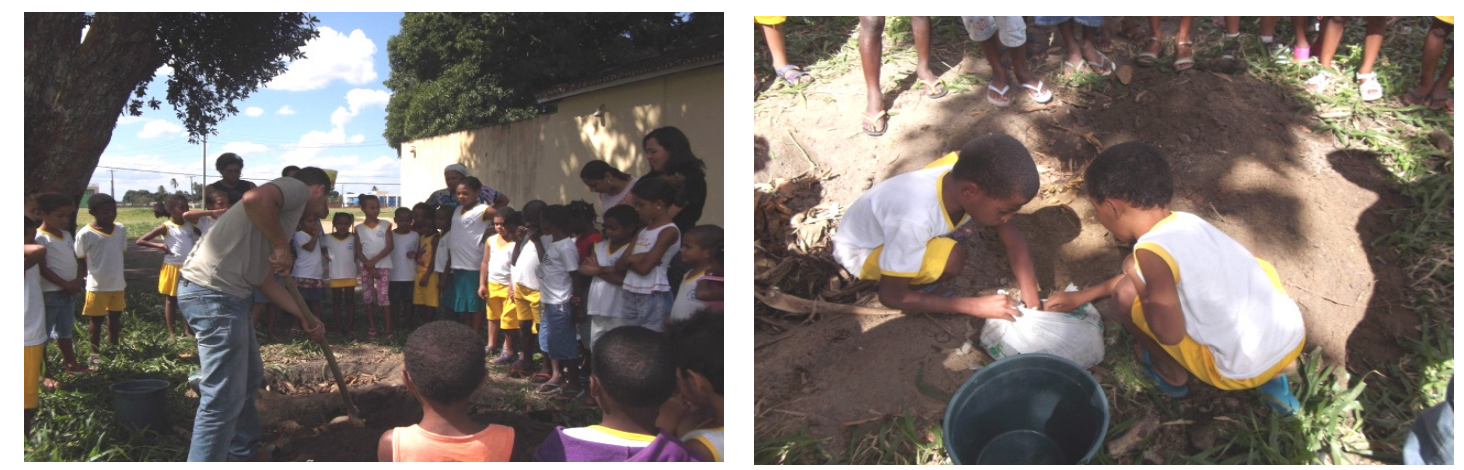

Figura 6: Alunos da escola Joaquim de Medeiros realizando a prática da compostagem.

Conforme Lima (2004), o composto produzido a partir dos resíduos orgânicos não representa necessariamente uma solução final para os problemas da escassez de alimentos ou do saneamento ambiental, mas pode contribuir significativamente como um elemento redutor dos danos causados pela disposição desordenada do lixo no meio urbano, além de propiciar a recuperação de solos agrícolas exauridos pela ação de fertilizantes químicos quando aplicados indevidamente.

A educação ambiental é fundamental para o sucesso de programas realizados para sensibilização da comunidade com relação aos resíduos sólidos. Através de programas educativos relacionados aos resíduos sólidos e que garantem seu uso racional, evita-se o agravamento de problemas ambientais gerados por esses resíduos.

No trabalho realizado por Santos et. al (2010) durante esse processo, o problema que os alunos do Centro Educacional Municipal Mário da Silva Pereira em Araguari-MG mais encontraram no espaço em que vivem foi à inadequada disposição de resíduos sólidos, que sujam as ruas, entopem bocas de lobo, representam o desperdício dentre outras situações. E as soluções mais apresentadas pelos mesmos foram àquelas relacionadas a informar os moradores dos bairros, sobre os problemas decorrentes do simples descarte do resíduo e até a realizar mutirões para limpar as ruas. Isso demonstra que existe uma preocupação por parte dos alunos com as situações que envolvem degradação ambiental. O próprio aluno foi levado a pensar e agir sobre o local, a cidade em que vivem e a compreender o seu papel na construção e preservação do Meio Ambiente. 
Dessa forma, a Educação Ambiental deve ser incorporada desde o Ensino Fundamental, com projetos na sala de aula levando conhecimento sobre o assunto aos alunos. Neste aspecto Britto (2000) destaca que, a escola é o ambiente mais propício para a abordagem de temas relativos à ecologia, saúde, higiene, preservação do meio ambiente e cidadania.

\section{CONSIDERAÇÕES FINAIS}

Este trabalho alcançou bons resultados a partir do momento em que foi possível transmitir aos alunos das escolas envolvidas conceitos e valores sobre o meio ambiente, geração e tratamento de resíduos sólidos por meio da reciclagem e compostagem bem como a sua adequada e inadequada disposição.

Com o desenvolvimento dessa pesquisa, foi possível observar que a participação da comunidade escolar no processo possibilitou a implantação de um programa de Educação Ambiental nas escolas envolvidas, o que levou à inserção na construção de novos modelos de gerenciamento de resíduos sólidos voltados à realidade local de Cruz das Almas.

Durante todo o trabalho foi possível, por meio das atividades práticas e das discussões teóricas, mostrar aos alunos as causas e consequências dos problemas ambientais.

Os alunos das escolas, envolvidos no projeto de Educação Ambiental, por meio da compostagem puderam vivenciar a transformação do resíduo orgânico, que antes parecia algo sem valor, em um novo produto. Foi possível observar a admiração destes no resultado obtido. Além disso, puderam ver o fruto de seu trabalho por meio do composto orgânico.

A Educação Ambiental é uma atividade que exige muitos esforços contínuos e que os educadores tenham tempo e interesse e por meio dessa pesquisa observou-se que tanto as escolas envolvidas como as visitadas, para posterior implantação do projeto, possuem pouco trabalho prático. Muitas vezes é necessário a presença de um pesquisador ou de um educador ambiental para que os professores saiam do seu cotidiano e tenham interesse em implantar um projeto, pois existem dificuldades dos professores em incorporar ao seu programa de aula as questões ambientais.

\section{REFERÊNCIAS}

ABREU, D.G.; CAMPOS, M.L.A. M.; AGUILAR, M.B.R. Educação ambiental nas escolas da região de Ribeirão Preto (SP): concepções orientadoras da prática docente e reflexões sobre a formação inicial de professores de química. Química Nova, v. 31, n. 3, p. 688-693, 2008.

AZEVEDO, C. J. C. Concepção e prática da população em relação ao lixo domiciliar na área central da cidade de Uruguaiana- RS. Uruguaiana, PUCRSCampus II, Monografia de pós-graduação. Educação ambiental. 1996.

Revbea, Rio Grande, V. 8, № 2:118-130, 2013. 
BIZERRIL, M.X.A.; FARIA, D.S. Percepção de professores sobre a educação ambiental no ensino fundamental. Revista Brasileira de Estudos Pedagógicos, Brasília, v. 82, n. 200/201/202, p. 57-69, 2001.

BRITTO, C. Educação e Gestão Ambiental. Salvador: Ministério do Meio Ambiente, 2000.

CARVALHO, I. C. M. "Ambiental" como valor substantivo: uma reflexão sobre a identidade da educação ambiental. In: SAUVÉ, L.; ORELLANA, I.; SATO, M. Textos escolhidos de educação ambiental: De uma América a Outra. Montreal, Publications ERE - UQAM, 2002, Tomo I, pp. 85-90 (versão em português).

CEMPRE - Compromisso Empresarial para a Reciclagem. Programa Bio Consciência. Lixo municipal - Manual de Gerenciamento Integrado. Brasília: CEMPRE, 2006.

FADINI, P.S.; FADINI, A.A.B. Lixo: desafios e compromissos. Cadernos temáticos de Química Nova na Escola. São Paulo: Sociedade Brasileira de Química. n. 1, maio de 2001. p. 9-18.

GUARIM, V.L.M.S. Barranco Alto: Uma experiência em Educação Ambiental. Cuiabá: UFMT, 2002.

LIMA, M.Q. Lixo: Tratamento e Biorremediação. São Paulo, 2004.

OLIVEIRA, M.S.J.L. et al. Meio ambiente e educação ambiental na percepção de professores de ensino fundamental e médio. BioFar Revista de Biologia e Farmácia, v.3, n.1, p. 88-104, 2009.

PENTEADO, H.D. Meio Ambiente e Formação de Professores. 6 ed. São Paulo: Cortez, 2007.

SANTOS, H.M.N.; BORGES, A.A.S.; CÂNDIDA, A.C.; FEHR, M. Educação ambiental e resíduos sólidos em Araguari/MG - Brasil. Revista da Católica, Uberlândia, v. 2, n. 3, p. 136-152, 2010.

TAVARES, L.J. Educação ambiental na escola pública: um relato de experiência. Extensio: Revista Eletrônica de Extensão, Florianópolis, n. 10, p. 43-56, 2010.

ZUBEN, F.V. Meio Ambiente, Cidadania e Educação. Departamento de Multimeios. Unicamp. Tetra Pak Ltda. 1998. 


\author{
ANEXO \\ Questionário - levantamento do perfil ambiental da escola \\ 01 - Nome da escola \\ 02- Nome do diretor (a) \\ 03- Tel. \\ 04- Quantos professores atuam na escola? \\ 05- Quantos alunos estão matriculados? \\ 06- Quantos residem na zona rural? \\ 07- A escola desenvolve projetos na área ambiental? \\ ( ) Sim \\ ( ) Não
}

08- Quais são os projetos que estão sendo desenvolvidos atualmente?

09- Quantos professores estão envolvidos no desenvolvimento dos projetos?

10- Como é a participação e o envolvimento dos alunos nos projetos?

11- Quais são as principais dificuldades encontradas pelos professores que desenvolvem projetos?

12- Os professores são incentivados e motivados para estarem desenvolvendo pequenos projetos ou atividades ambientais com seus alunos?

13- A escola possui área arborizada, horta, ou outros espaços que poderão ser utilizados para trabalhar Educação Ambiental?

14- $\mathrm{Na}$ escola existe o processo de separação do lixo produzido pela comunidade escolar?

15- O que é feito com o lixo separado?

16- Os professores realizam atividades com os alunos fora da escola? Quais são os principais locais utilizados pelos professores?

17- A escola realiza visitas a campo, para trabalhar a realidade local sobre as questões ambientais? 